\title{
What makes granulomas tick?
}

\author{
D Geraint James
}

The pine pollen theory of sarcoidosis was all the rage in the 1960s. Martin Cummings ${ }^{1}$ had presented a most attractive and plausible explanation of the geographical distribution and prevalence of sarcoidosis in the south eastern United States. After considerable painstaking shoe leather epidemiology, he had shown that the distribution of sarcoidosis correlated well with the pine forests of the United States. Furthermore, pine pollen had acid fast staining qualities similar to those of Mycobacterium tuberculosis. Chemical studies revealed the presence of long chain fatty acids and a substance similar to the "wax" fraction of the tubercle bacillus. Suspensions of pine pollen injected into the skin of guinea pigs produced sarcoid granulomas; pine pollen inhalations by rabbit lungs produced granulomatous foreign body giant cell reactions; and its intravenous injection produced granulomas in the lungs and liver of rats. Lipid containing extracts caused granulomas whereas whole pine incited foreign body reactions.

At this time, Edith Mankiewicz ${ }^{2}$ was producing granulomas from "atypical" mycobacteria and Chapman ${ }^{3}$ was drawing attention to the frequency of mycobacterial antibodies in serum from patients with sarcoidosis. Hartston ${ }^{4}$ was able to reproduce Kveim granulomas in patients by using various fatty acids, particularly trimethyl docosanoic acid, and generalised granulomatosis in guinea pigs with BCG and with lipid extracts of tubercle bacilli. We produced Kveim granulomas in patients with sarcoidosis using tuberculolipopolysaccharide, but they could also be induced in healthy tuberculin positive control subjects. It became apparent that granuloma formation could be induced by various agents, including bacteria, fungi, viruses, helminths, chemicals, BCG vaccine, and even carcinoma. Thus a sense of non-specificity enveloped the whole subject, and the theory that pine pollen lipopolysaccharide was the cause of sarcoidosis, attractive though it was, was laid to rest.

Attention then switched to immunology of a very simple kind, suitable for the bedside investigator. The relation between sarcoidosis and tuberculosis had always provided emotional overtones at meetings and in practice. Although clinical aspects and treatment differed, the chest radiographs were often confusingly similar. At the bedside, tuberculin and dinitrochlorobenzene skin tests highlighted the depression of delayed type hypersensitivity that was characteristic of sarcoidosis. ${ }^{5}$ Tuberculosis patients, on the other hand, had normal delayed type hypersensitivity except for an interesting small group of non-reactive or anergic subjects. The other distinguishing feature was the Kvein-Siltzbach skin test, which gave a positive reaction in sarcoidosis and a negative one in tuberculosis.

More sophisticated techniques of immunology and molecular biology have now led to a resurgence of interest in granuloma formation and to the antigens contributing to it. Antigenic invasion by microorganisms, chemicals, or cancer may be met by a granulomatous inflammatory response, which depends on close interplay between activated macrophages bearing increased expression of major histocompatibility (MHC) class II molecules and CD 4 TH lymphocytes. These $\mathrm{T}$ helper cells recognise only those proteins presented to it by antigen presenting cells bearing MHC class II molecules and these are largely restricted to macrophages. The dual signal of the MHC molecule-antigen complex and interleukin 1 , secreted by the macrophage, activates the $T$ cell, causing a cascade of other cytokines to be produced, which may enhance or suppress macrophage function. For example gamma $(\gamma)$ interferon, secreted by the $\mathrm{T}$ lymphocyte, has a positive back action on the macrophage, increasing the expression of MHC class II molecules. Activated macrophage receptors carry an Fc fraction of IgG to potentiate their ability to phagocytose and kill. Whereas $T$ cells and macrophages are abundant at the site of sarcoid inflammation, they are less evident away from this battlefield. In the peripheral circulation there may be lymphopenia with an absolute decrease in $\mathrm{T}$ helper cells. Bronchoalveolar lavage shows lymphocytic alveolitis with accumulation of macrophages and $T$ cells within the alveolar structure.

Monoclonal antibodies have been used to differentiate $T$ cells into subsets and this technique is now helping to differentiate macrophages. RFD1 monoclonal antibodies recognise dendritic cells and RFD7 recognise mature macrophages. It now appears that cells with the double phenotype $\mathrm{RFD} 1^{+} \mathrm{D}^{+}$may have an important immunomodulatory role in sarcoid inflammation, perhaps under the 

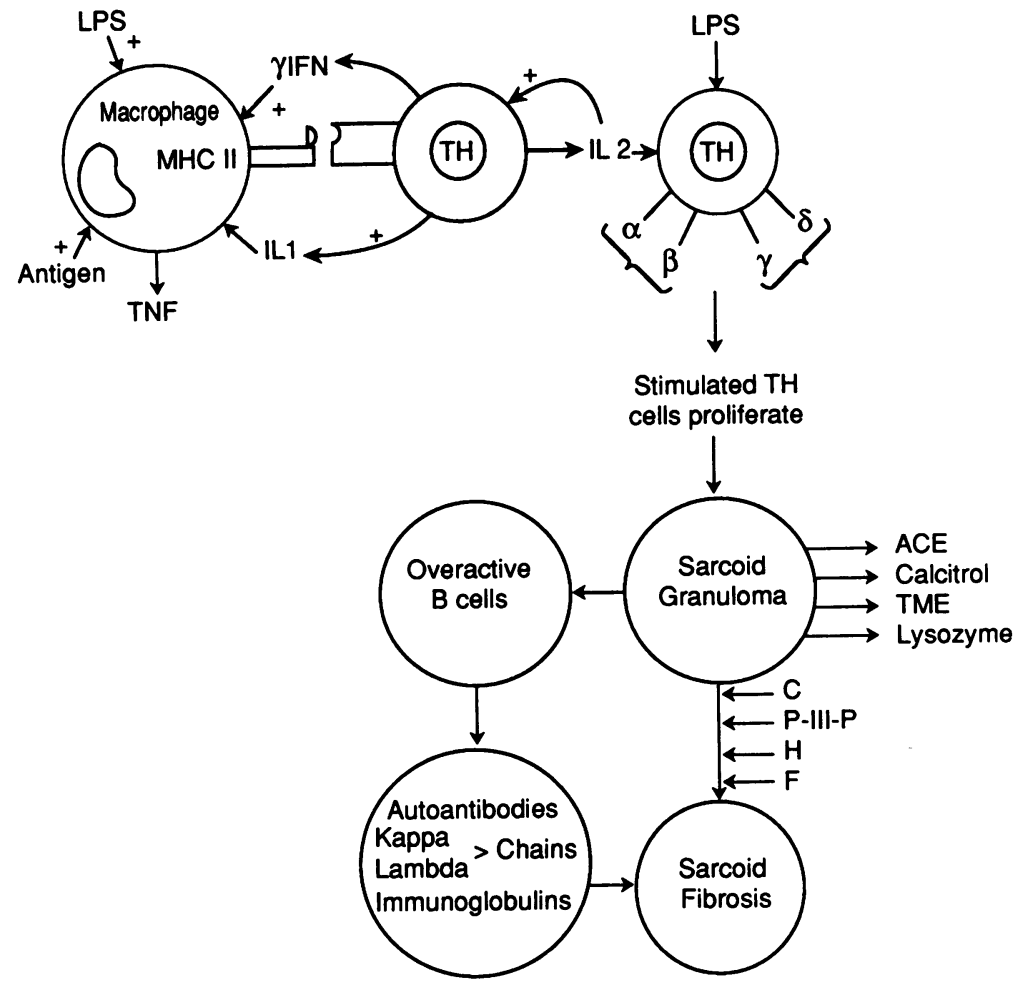

Sarcoid granuloma: interplay between macrophages, $T$ and $B$ cells, and cytokinases. LPS-lipopolysaccharide; $\gamma$ IFN-gamma interferon; $M$-macrophage; $T H$-thymu mediated helper cell; IL1/2-interleukins 1 and 2; TNF-tumour necrosis factor; $A C E$-angiotensin converting enzyme; TME-metallopeptidase; $P-I I I-P$ - type III procollagen $N$ terminal peptide; $C$-collagenase; $H$-hyaluronic acid; $F$-fibronectin.

influence of interferon, which is a potent activator of HLA-DR molecular expression on the surface of macrophages. . $^{6-10}$

Just as subpopulations of macrophages are repaying closer scrutiny, $T$ cell subsets are providing rewarding information on granuloma formation. Most $\mathrm{T}$ cells bear the $\mathrm{T}$ cell receptor (TCR) $\alpha \beta$ complex but a small subpopulation of about $5 \%$ bear a distinct $\mathrm{T}$ cell receptor composed of $\gamma$ and $\delta$ subunits in lymphoid organs and skin. This separate lineage of $\gamma \delta \mathrm{T}$ cells is activated by Mycobacterium tuberculosis and the response does not require recognition of major HLA class II antigens. ${ }^{11}$ This small subpopulation of T cell receptor $\gamma \delta$ lymphocytes is prominent in three other granulomatous disorders-namely, leprosy, leishmaniasis, ${ }^{12}$ and sarcoidosis. ${ }^{1314}$ They accumulate in reactive granulomatous lesions of leprosy and local cutaneous leishmaniasis, and when cultured from leprosy lesions they proliferate in response to mycobacterial antigens in vitro. When stimulated by antigen they secrete lymphokines that cause macrophage adhesion, aggregation, and proliferation. This distinct population of T cell receptor $\gamma \delta$ lymphocytes seems likely to take an active part in the granulomatous inflammatory response of many granulomatous disorders.

What of the lymphokines taking part in this reaction? Tumour necrosis factor has been studied in granulomatous lung disease in Japan, particularly tuberculosis and sarcoidosis. ${ }^{15}$ Tumour necrosis factor activity in serum, bronchoalveolar fluid, and supernatants of cultured monocytes was determined by the ELISA method with anti-tumour necrosis factor monoclonal antibody. No differences were noted between patients with tuberculosis or sarcoidosis and controls in the tumour necrosis factor activity in serum or bronchoalveolar lavage fluid. Tumour necrosis factor activity was higher in supernatants of cultured monocytes taken from patients with tuberculosis and sarcoidosis than from controls, and this was true also of supernatants of cultured macrophages in the presence of lipopolysaccharide. This provides further evidence of lymphokine activity in response to mycobacterial antigens in granulomatous lung disease.

Crystal and his coworkers ${ }^{1314}$ have found an overrepresentation of $\gamma \delta \mathrm{T}$ cells in blood and lung $T$ cells in sarcoidosis, and have put forward a reasonable hypothesis on the pathogenesis of this granulomatous disorder. They suggest that $\gamma \delta \mathrm{T}$ cells respond to antigenic challenge by mycobacteria, parasites, mycobacterial proteins, and heat shock proteins, and that one of these initiates the immune response that snowballs onwards to multisystem sarcoidosis (figure). Those who have lived through the long history of claims for mycobacteria or their mucopolysaccharides or other chemical components may now reflect ruefully that we may now be back to square one in our search for the cause of sarcoidosis. It has been suggested that $\gamma \delta \mathrm{T}$ cells provide a rapid primary immune response to antigenic invasion until specific $\alpha \beta \mathrm{T}$ cells expand and take over. It is tempting to relate this initial immune response to the Kveim-Siltzbach skin test. Serial biopsies of Kveim sites should provide an answer. Further studies should also show whether certain $\mathrm{T}$ and $\mathrm{B}$ cell subsets are associated with different clinical manifestations, such as Sven Lofgren's syndrome of erythema nodosum with hilar adenopathy, lupus pernio, and uveitis.

1 Cummings MM. An evaluation of the possible relationship of pine pollen to sarcoidosis (a critical summary). In: Lofren S, ed. In: Proceedings of the Third International Conference on Sarcoidosis. Acta Med Scand 1964;suppl 425:48-50.

2 Mankiewicz E, Kurti V. Immunologic defects in patients with sarcoidosis. In: Levinsky L, Macholda F, eds. Proceedings of the Fifth International Conference on Sarcoidosis. Prague: Universita Karlova, 1971:224-5.

3 Chapman JS. The pathogenesis of granuloma formation. In: Levinsky L, Macholda F, eds. Proceedings of the Fifth International Conference on Sarcoidosis. Prague: Universita Karlova, 1971:105-9.

4 Hartston $W$. Studies in experimental sarcoidosis. In: Levinsky L, Macholda F, eds. Proceedings of the Fifth International Conference on Sarcoidosis. Prague: Universita Karlova, 1971:73-5.

5 Sharma OP, Bailey AR, Doe WF, James DG. Immunological relationships between sarcoidosis and tuberculosis. In: Levinsky L, Macholda F, eds. Proceedings of the Fifth International Conference on Sarcoidosis. Prague: Universita Karlova, 1971:181-2.

6 James DG, Jones Williams W. Sarcoidosis and other granulomatous disorders. Philadelphia: WB Saunders, 1985.

7 Poulter LW. Immune aspects of sarcoidosis. Postgrad Med J 1988;64:536-43.

8 Spiteri M, Poulter LW, James DG. The macrophage in granuloma formation. Sarcoidosis 1989;6(suppl 1):12-4.

9 Modlin RL, Hofman FM, Meyer PR, Sharma OP, Taylor CR, Rea TH. In situ demonstration of $T$ lymphocyte subsets in granulomatous inflammations: leprosy, rhinoscleroma and sarcoidosis. Clin Exp Immunol 1983;51: 430-8. 
10 Mishra BB, Poulter LW, Janossy G, James DG. The distribution of lymphoid and macrophage-like cell subsets of sarcoid and Kveim granulomata: possible mechanisms
of negative PPD reactions in sarcoidosis. Clin Exp Immunol 1983;54:705-15.

11 James EM, Kaufmann SHE, Schwartz RH, Pardoll DM. Activation of $\gamma \delta$ T cells in the primary immune response to Mycobacterium tuberculosis. Science 1989;244:713-6.

12 Modlin RL, Pirmez C, Hofman FM, Rorigian T, Uyemura $\mathrm{K}$, Rea TH, et al. Lymphocytes bearing antigen-specific $\gamma \delta$ $\mathrm{T}$-cell receptors accumulate in human infectious disease lesions. Nature 1989;339:544-8.
13 Balbi B, Moller DR, Kirby M, Holroyd K, Crystal RG Increased numbers of $\mathrm{T}$ lymphocytes with $\gamma \delta \mathrm{T}$ antigen receptors in a subgroup of individuals with pulmonary sarcoidosis. J Clin Invest 1990;85:1353-61.

14 Tamura N, Holroyd KJ, Banks T, Kirby M, Okayama $\mathrm{H}$ Crystal RG. Diversity in junctional sequences associated with the common human $\mathrm{V}_{y} 9$ and $\mathrm{V} \delta_{2}$ gene segment in normal blood and lung compared to the limited diversity in a Granulomatous Disease. $J$ Exp Med 1990;172:169-81. 15 Miyachi A, Noda M, Ina Y, Takada S, Iijima N, Kakihara H Hashiba $\mathrm{H}$, et al. Tumour necrosis factor in granulomatous lung disease. Sarcoidosis 1989;6:80. 